\title{
Reliability and Validity of the NIMHANS Index of Specific Learning Disabilities
}

\author{
Anuja S. Panicker ${ }^{1}$ \\ Snigdhasree Bhattacharya ${ }^{2}$ \\ Uma Hirisave ${ }^{3}$ \\ Nalini N.R. ${ }^{4}$ \\ ${ }^{1}$ Associate Professor, PSG Institute of Medical Sciences and Research, Coimbatore, Tamil Nadu. \\ ${ }^{2}$ PhD Scholar, Department of Clinical Psychology, NIMHANS, Bangalore. \\ ${ }^{3}$ Professor, Department of Clinical Psychology, NIMHANS, Bangalore. \\ ${ }^{4}$ Clinical Psychologist and Private Practitioner (PhD - NIMHANS), Bangalore. \\ E-mail-snigdhab1@yahoo.com
} \begin{abstract}
The present study, aims to establish the reliability and validity of the NIMHANS Index for Specific Learning Disabilities (SLD) for a sample of children with SLD. The NIMHANS Index for Specific Learning Disabilities was initially developed by Kapur, John, Rozario and Oommen in 1991 in the Department of Clinical Psychology, NIMHANS, Bangalore. The study was conducted on a sample of 40 children selected from the Child and Adolescent Mental Health Unit, (CAMHU), NIMHANS after meeting the inclusion criteria of the study. Each child was individually assessed using MISIC and NIMHANS SLD index. The parents were also seen separately and administered the DPCL. They were also asked to bring the Checklist for School Report completed by the class teacher. Out of the 40 children tested, 35 children were confirmed as having Specific Learning Disability and five did not SLD as per the NIMHANS Index for SLD. There was significant correlation between teachers rating and clinical rating when compared with the presence of SLD. There was moderate association found between severities of SLD as assessed on the NIMHANS Index Specific Learning Disabilities with the Parental rating on the Learning Difficulties subscale of the DPCL.
\end{abstract}

Key words: Specific Learning Disabilities, NIMHANS Index of Specific Learning Disabilities, Reliability and Validity of NIMHANS Index of Specific Learning Disabilities, $S L D$ in the Indian Context.

\section{INTRODUCTION}

As per WHO, 1992, Specific Developmental Disorders of Scholastic Skills (SDDSS) refer to those conditions where patterns of scholastic skills acquisition are disturbed since early stages of development inspite of adequate opportunity to learn and in the absence of brain trauma. The term SDDSS is used interchangeably with the term 'Specific Learning Disability' (SLD). 
The term learning disabilities emerged from a need to identify and help children who repeatedly show poor scholastic performance, yet are not mentally retarded. Epidemiological research reveals that 3-6\% of school age children most likely to suffer from a learning disability [1]. In the Indian context, prevalence rates are estimated to range between $9-39 \%$ [2-3]. Considering the high prevalence of SLD in Primary School Children, it is important that an effective tool be used for assessment of SLD. The NIMHANS Index for Specific Learning Disabilities was initially developed by Kapur, John, Rozario and Oommen in 1991 in the Department of Clinical Psychology, NIMHANS, Bangalore [4]. This tool has been used in a number of studies to confirm the diagnosis of SLD and differentiate children with SLD and those without. The SLD index has been mainly used to confirm the diagnosis of SDDSS made by the clinical psychologist as per the ICD- 10 criteria to enable to children to get benefits offered by the State Government. Unlike Western achievement tests, where it is possible to arrive at a percentile point as well as derive age appropriate grades, the NIMHANS SLD index is a curriculum based assessment.

The Usefulness of a tool cannot be commented upon unless its statistical properties have been established. The aim of the current study was to establish the reliability and validity of the NIMHANS Index for Specific Learning Disabilities for a sample of children with SLD.

\section{METHODOLOGY}

\section{Sample}

The sample consisted of 40 children (Boys and girls) taken from the Outpatient department of the child and Adolescent Mental Health Unit (CAMHU) of the Institute.

\section{Inclusion Criteria}

- Age between 6 years - 16 Years at the limit of first contact

- Diagnosis of average to above intelligence on Axis III of Rutter's multi-axial classification

- Children diagnosed as have Specific Disabilities or difficulties on the Axis II of Rutter's multi-axial classification.

\section{Exclusion Criteria}

Children with comorbid Attention Deficit Hyperactivity Disorder, Emotional Disorder, Conduct Disorder, Dissociative Disorder or Eating Disorder on Axis I.

\section{Tools Used}

\section{NIMHANS Index for specific Learning Disabilities}

The NIMHANS index for Specific Learning Disabilities was developed in the Department of Clinical Psychology, NIMHANS, Bangalore. It was initially developed by Kapur, John, Rozario and Oommen in the year 1991 to screen children with SLD. The NIMHANS Index for Specific Learning Disabilities consists of tests of reading, writing, spelling and arithmetic abilities, to identify children with disabilities in these areas. It consists of two levels:

Level I: Consisting of tests of Attention, visual Discrimination, Visual Memory, Auditory Memory, Speech and Language, Visuo- motor skills and Writing Skills.

Level II: Consisting of tests of Attention, Language (Reading, writing, Comprehension), Spelling, Perceptual Motor Abilities, Memory and Arithmetic. 
The battery has norms for children in Std. I-V [4]. This battery has been used for confirming an initial diagnosis SLD as well as for Certification of these children to enable them to avail benefits as per the government order. The tool has been used in several studies to compare the psychological characteristics of children having SLD and normal children [5-8]. It has also been used for assessment of improvement after remediation [9-10].

For the purpose of the present study, children whose performance was below (less than two standards) their expected grade were considered as having mild SLD. Those whose performance was much below (less than four standards) their expected grade were considered as having severe SLD.

\section{Developmental Psychopathology Checklist for Children (DPCL)}

The Developmental psychopathology Checklist has been Standardized on 221 children below 16 years of age. The DPCL consists of 124 items divided into six subsections: (1) Developmental History, (2) Developmental Problems, (3) Psychopathology, (4) Psychosocial Factors, (5) Temperamental Dimensions and (6) Helpful Factors. The psychopathology subsection consists of items pertaining to Attention Deficit Hyperactivity Disorder, Conduct Disorder, and Learning Difficulties subscale were used for the present study. The reliability of these scales has been found to be 0.96 . Criterion Validity on comparison with the child Behavior Checklist $(\mathrm{CBCL})$ has been established [2].

\section{Malin's Intelligence Scale for Indian Children (MISIC)}

Malin's Intelligence Scale for Indian Children (MISIC) is the Indian adaptation of the Wechsler Intelligence Scale for Children (WISC). The test has been standardized the MISIC on 1,200 children [11]. It consists of 11 subsets, classified into Verbal and Performance Subsets. The test- reset reliability is 0.91 (FSIA) concurrent as well as congruent validity have also been established. This tool has been widely used in the Indian context for assessing intellectual abilities in Children.

\section{Checklist for School Report}

This Checklist for School Report is routinely used in the CAMH (Child and Adolescent Mental Health), NIMHANS to get the teacher's evaluation of the child's academic performance, consisting of items related to: (1) Overall performance in Class, (2) Regularity in classwork, (3) Difficulty in paying attention in class, (4) Presence of specific difficulties in reading, writing and arithmetic, (5) Social interaction with other classmates and (6) Any other comments regarding the child. For the purpose of the current study, this tool was used for comparing the teacher's evaluation of specific learning difficulty with the child's reading, writing and arithmetic abilities. Thus, item 4 on this checklist was used to obtain the teacher's evaluation regarding the presence or absence of Specific Learning Disability in reading, writing and Arithmetic.

\section{Statistical Analysis}

Test-retest reliability of the NIMHANS Index for Specific Learning Disabilities was determined by comparing assessment post assessment scores using Intraclass Correlation Coefficient (ICC). Criterion validity was computed by comparing the teacher's rating and Clinical rating with the child's performance on NIMHANS Index for specific Learning Disabilities using Pearson's correlation coefficient. Chi-Square was also used to determine the association between parental rating on DPCL and severity of SLD as assessed using the NIMHANS Index for Specific Learning Disabilities. 


\section{Procedure}

The sample was taken from the Child and Adolescent Mental Health Unit, (CAMHU), NIMHANS. The children were individually evaluated by the Post Graduate trainees using the Child and Adolescent Mental Proforma. The diagnosis was confirmed by the Child Psychiatry consultants (who have more than 20 years of experience in child and adolescent health).

Forty children were selected as per the inclusion and exclusion criteria. They were called for assessment during the same week of their registration in CAMHU. They were also asked to bring the Checklist for School Report completed by the class teacher.

Each child was individually assessed using MISIC and NIMHANS SLD index. The parents were also seen separately and administered the DPCL. All assessments were carried out by a Clinical Psychologist with adequate training in child assessment.

After assessment all forty children and their parents were given feedback about the nature of difficulties. The parents and teachers were counseled regarding possible causes for the child's difficulties' in scholastic performance and on different methods of remediation in a supportive framework. They were given exemption certificate to seek exemption from second and third languages in accordance with the Karnataka Government Order. The parents were offered further sessions of counseling as well sessions for remediation for the child.

Out of the 40 children tested, 35 children were confirmed as having Specific Learning Disability and five did not SLD as per the NIMHANS Index for SLD. Of these 35 children, five children underwent remediation sessions.

Thirty children who did not avail of any type of remediation, either in NIMHANS or outside, were contacted for post assessment, after 6 months to assess test-retest reliability. Some of the reasons cited for not availing remedial services were: lack of remedial center either at their school or near their residence and financial burden.

\section{RESULTS}

The sample characteristics of the children are indicated in Table 1. Table 1 indicates that the children in the present sample range from 6-16 years of age. Majority of children were studying in English medium, state syllabus schools.

The Assessments findings are indicated in Table 2. It was found that using the NIMHANS SLD battery, $88 \%(\mathrm{~N}=35)$ of children were diagnosed as having Specific Learning Disability (SLD). Table 2 shows the similarity in findings when NIMHANS Index for Specific Learning Disabilities, Teacher and clinical ratings were compared.

Significant correlation was present Teachers rating and clinical Rating was compared with the presence of SLD (Table 3). This indicates the high criterion validity of the NIMHANS Index for Specific Learning Disabilities with Teacher and Clinical Rating. Table 4 Indicates moderate association between severities of SLD as assessed on the NIMHANS Index Specific Learning Disabilities with the Parental rating on the Learning Difficulties subscale of the DPCL. Table 5 indicates high test-retest reliability for the NIMHANS Index for Specific Learning Disabilities with respect to severity of SLD. 
Table 1 - Sample Characteristics

\begin{tabular}{|c|c|c|c|}
\hline & Variable & Frequency & Percentage \\
\hline \multirow{2}{*}{ Sex } & Male & 29 & 73 \\
\hline & Female & 11 & 27 \\
\hline \multirow{4}{*}{ Age (years) } & $6-8$ & 5 & 12 \\
\hline & $9-11$ & 15 & 38 \\
\hline & $12-14$ & 16 & 40 \\
\hline & $15-16$ & 4 & 10 \\
\hline \multirow{2}{*}{$\begin{array}{l}\text { Medium of } \\
\text { Instruction }\end{array}$} & English & 38 & 95 \\
\hline & Kannada & 2 & 5 \\
\hline \multirow{3}{*}{ Class } & Primary & 8 & 20 \\
\hline & Middle & 17 & 43 \\
\hline & High & 15 & 37 \\
\hline \multirow{2}{*}{ Place } & Bangalore & 34 & 85 \\
\hline & Outside Bangalore & 6 & 15 \\
\hline \multirow{5}{*}{ Mother Tongue } & Kannada & 18 & 45 \\
\hline & Telugu & 10 & 25 \\
\hline & Tamil & 8 & 20 \\
\hline & Urdu & 3 & 7 \\
\hline & Tamil & 1 & 3 \\
\hline \multirow{3}{*}{ Syllabus } & State & 33 & 83 \\
\hline & ICSE & 4 & 10 \\
\hline & CBSE & 3 & 7 \\
\hline
\end{tabular}

Table 2 - Assessment findings $(n=40)$

\begin{tabular}{|ccccc|}
\hline \multirow{2}{*}{ Variable } & \multicolumn{2}{c}{ SLD Present } & \multicolumn{2}{c|}{ SLD Absent } \\
\cline { 2 - 5 } & $\mathrm{N}$ & $\%$ & $\mathrm{~N}$ & $\%$ \\
\hline NIMHANS SLD battery & 35 & 88 & 5 & 12 \\
\hline Teacher Rating & 37 & 92 & 3 & 8 \\
\hline Clinical Rating & 38 & 95 & 2 & 5 \\
\hline
\end{tabular}

Table 3 - Presence of SLD versus teacher rating and clinical rating $(n=40)$

\begin{tabular}{|ccccc|} 
& \multicolumn{2}{c}{ Teacher rating } & \multicolumn{2}{c|}{ Clinical rating } \\
& $\boldsymbol{r}$ & Significance & $\boldsymbol{r}$ & Significance \\
\hline $\begin{array}{c}\text { Presence of } \\
\text { SLD }\end{array}$ & $0.75 * *$ & 0.01 & $0.61 * *$ & 0.01 \\
\hline
\end{tabular}

**significant 
Table 4 - Parental rating compared with severity of SLD $(n=40)$

\begin{tabular}{|c|c|c|c|c|}
\hline SLD Severity & \multicolumn{2}{|c|}{ Parental rating (DPCL) } & \multirow[t]{2}{*}{ Total } & \multirow{2}{*}{$\begin{array}{c}\mathbf{X}^{2} \\
\text { (sig.) }\end{array}$} \\
\hline (NIMHANS SLD Index) & $<$ cutoff & $>$ cutoff & & \\
\hline Nil & 2 & 3 & 5 & \multirow{4}{*}{$\begin{array}{c}035 \\
(0.06)\end{array}$} \\
\hline Mild & 1 & 18 & 19 & \\
\hline Moderate/ Severe & 1 & 15 & 16 & \\
\hline Total & 4 & 36 & 40 & \\
\hline
\end{tabular}

Table 5 - Test-retest reliability $(n=30)$

\begin{tabular}{|ccc|}
\hline Variable & R value & Significance \\
\hline SLD severity & $\mathbf{0 . 5 3 * * *}$ & $\mathbf{0 . 0 0 1}$ \\
\hline & $* * *(\mathrm{p}<0.001)$ & \\
\hline
\end{tabular}

\section{DISCUSSION}

The present study, aimed to establish the reliability and validity of the NIMHANS Index for Specific Learning Disabilities for a sample of children with SLD. In keeping with the current understanding of models (cognitive and neuropsychological) offered for assessment of learning disability [12], it is important to keep in mind the response to intervention model and develop a test which lends itself to test pre and post assessment following intervention.

In the Indian educational system, there is a lot of heterogeneity in the inputs given. Often children are promoted to higher classes even when they are not appropriate. Because of these inherent problems, it is difficult to devise a test that can reliably and validly classify children with SLD, due to the vast difference in the inputs they get. Lack of early intervention in majority of the schools further complicated their education. Keeping these difficulties in mind, the NIMHANS Index for SLD was developed. The test is based on the Karnataka State Syllabus which is far simpler especially when compared with CBSE or ICSE. (Majority of the children seen in Child and Adolescent Mental Health clinic study in the state syllabus board making it an appropriate test). It has a modest goal of screening children with SLD and it should not be used for sub typing of SLD or for identification of those who would respond for intervention. Assessment of the test-retest reliability of the test indicated that there was high significant correlation (0.53) between test findings after a gap of 6 months, indicating high temporal consistency of the test. Criterion validity was established by comparing the NIMHANS Index for Specific Learning Disabilities findings the Teacher and Clinical ratings. Teacher rating was based on a letter from the teacher in which he/she rated the child's academic performance. Clinical Rating was based on the diagnosis with respect to Learning Disability given by CAMH Unit prior to assessment. The correlations of these ratings with findings on the NIMHANS Index for Specific Learning Disabilities were found to be 0.61 respectively. Both correlations were found to be highly significant.

On comparison of parental rating of the child's learning difficulties with the severity of SLD as assessed by the NIMHANS Index, only moderate association was present. This can be because the DPCL is a tool for screening psychopathology and not learning disability in detail. Thus comparison with a different standardized test specifically used for assessment of learning disability could have been used for a more reliable measure of concurrent validity. One limitation is the small sample size for the 
study. However it is understandable considering the nature of the test, which is individually administered, detailed, comprehensive and time consuming (requires over 4 hours for testing). However this limitation lends itself for scope for future research. It would be interesting to have a follow up study of the children with SDDSS, to understand better the application and success of intervention. Research could also focus on development of a test which will help in sub typing learning disabilities. This will further enable specific intervention for specific subtypes of learning disabilities.

There is clearly scope for extending the work further by developing an index for assessment of scholastic difficulties on older children (above 13 years of age) as there is a clear rise in the number of older children who report with learning problems, which may be attributed to reasons like grace promotion, and rote based learning without conceptual understanding. Overall, the current study definitely highlights that the NIMHANS Index for specific Learning Disabilities has high test-retest reliability and criterion validity. The test is thus a valid and reliable tool for assessment of Specific Learning Disabilities in children.

\section{REFERENCES}

1. Koegh BK(1986). A marker system for describing learning disability samples. Cited in A. Lall, Perceived peer relations, parenting and social competence in children with academic skill difficulties, M.Phil dissertation, NIMHANS, Bangalore (1996).

2. Rao DG. A study of some factors related to scholastic achievement. Indian Journal of Psychology 1970;45:99-120Agarwal KM, Agarwal DK, Upadhyay SK, Singh M. Learning disabilities in rural primary school children. Indian J Med Res 1991;94:89-95.

3. Kapur M, Barnabas S, Reddy MV, Rosario J and Hirisave U (1995). Developmental Psychopathology checklist for children (DPCL) - A preliminary report, NIMHANS Journal, 13, 1-9.

4. Kapur M, John A, Rozario J, Oommen A, Uma H. (2002). Assessment of specific learning disabilities. In Hirisave $U$, Oommen A, Kapur, M. (eds), Psychological Assessment of Children in the clinical Setting. Bangalore: Vinayaka Offset Printers.

5. Bhola P, Uma H, Kapur M, Subbakrishna DK, (2000). Self-perception in children with Scholastic Skills Disorders. Indian Journal of Clinical Psychology; 27: 249-253

6. Lall A, Uma H, Subbakrishna DK. (1997). Perceived peer relations, parenting and social competence in children with specific disorders of scholastic skills. NIMHANS Journal; 15 : 133-137.

7. Mukerjee S, Uma H, Kapur M, Subbakrishna DK. (1995) Anxiety and self-esteem in children with Specific Disorders of Scholastic Skills. NIMHANS Journal; 13: 117-121.

8. Poddar N. (1999). Relationship of cognitive behavioral functioning and quality of life in children with epilepsy. Unpublished M.Phil dissertation submitted to National Institute to National Institute of Mental Health and neurosciences (NIMHANS), Bangalore.

9. Rozario J. (1991). Intervention strategies for scholastic back-wardness. Unpublished Ph.D. thesis submitted to Bangalore University, National Institute of Mental Health and Neurosciences (NIMHANS), Bangalore.

10. Shanti K, Uma H, Reddy MV. (1999). Behaviour problems and disciplining among children with scholastic skill difficulties. NIMHANS Journal; 17:11-18.

11. Malin AJ. (1969). Manual of Malin's Intelligence Scale for Indian Children (MISIC), Lucknow; Indian Psychological Corporation.

12. Fletcher JM, Francis DJ, Morris RD \& Lyon GR. (2005). Evidence based assessment of learning disabilities in children and adolescents. Journal of Clinical Child and Adolescent Psychology; 3, 506-522.

Acknowledgements - Nil; Conflict of Interest - Nil; Funding - Nil. 